\title{
Effect of Some Structural Parameters on Firing Stability of Shooter-Weapon System
}

\author{
B. Van $\mathrm{Vo}^{1 *}, \mathrm{P}$. Van $\mathrm{Ta}^{1}$ and M. Macko ${ }^{2}$ \\ ${ }^{1}$ Department of Weapons, Le Quy Don Technical University, Hanoi, Viet Nam \\ ${ }^{2}$ Department of Weapons and Ammunition, the University of Defence, Brno, Czech Republic
}

The manuscript was received on 23 February 2021 and was accepted after revision for publication as research paper on 2 July 2021.

\begin{abstract}
:
This article presents a method to establish the dynamic model of the Shooter-weapon system when firing based on Lagrange's theorem and the theory of multibody system dynamics, in which the influence of the human body was taken into account. In the dynamic model, the influence of the gunner is solved by using elastic-damping links in the $x, y$ and $z$ axes. The dynamic model is created for a portable gas-operated submachine gun and contains three solids with seven degrees of freedom. The $7.62 \mathrm{~mm}$ AKM submachine gun has been used for the model simulation and experimental verification. The dynamic simulation was conducted and then the results were compared with the corresponding experimental data. The model simulation results are very close to the experimental results. This study aims to survey the influence of various parameters on gun stability in the shooting. It is possible to apply these results to portable automatic guns.
\end{abstract}

\section{Keywords:}

Shooter-weapon system, firing stability, Lagrange equation, automatic weapon, dynamics, the $7.62 \mathrm{~mm}$ AKM

\section{Introduction}

Studies on the oscillation of the mechanical Shooter-weapon system when shooting play an important role since it is essential to analyze gun stability impact on shooting. Many pieces of research on this issue have been done, and some most notable ones are presented in [1-5]. However, the latest model can only examine the system in two planes: vertical and horizontal, see [2]. The previous research models have only partly dealt with the effect of the shooter's hands, such as just calculating the effect of the shooter's left hand on the mechanical system. Therefore, a model with valid research studies was necessary to examine the influences of the shooter's body on the firing stability.

\footnotetext{
* Corresponding author: Department of Weapons, Le Quy Don Technical University, Hoang Quoc Viet 236, Hanoi, Vietnam. Phone: +420 7774015 84, E-mail: vovanbien.mta@ gmail.com
} 
In this paper, the dynamic model of the Shooter-weapon system is described. The theoretical part creates a spatial model of the dynamics of a multibody system using the Lagrange movement equations method, which considers the influence of the human body. Using this model to investigate the Shooter-weapon system gives us a more comprehensive view of the system stability in the relationship between displacement, external load, and boundary link. These results are essentialfor the process of development, innovation, new designs, and solutions to improve gun firing accuracy.

\section{Problem Formulation}

\subsection{Proposed Dynamic Model of Shooter-Weapon System Description}

The dynamic model has been made up by using the following assumptions:

- details and assemblies are considered rigid bodies. The mass of objects is placed at the center of the object or center of gravity,

- forces of shooter acting on the mechanical system are modeled as a viscouselastic system in 3 translational directions with the corresponding coefficients of $k$ and $b$. Using this assumption, we can replace the effects of the shooter's shoulder by a spring with stiffness $k_{\mathrm{s} j}$ and damping with viscous resistance coefficient $b_{s j}$ and replace the effects of the shooter's hands by another spring with stiffness $k_{\mathrm{tj}}$ and damping with a viscous coefficient of resistance $b_{\mathrm{tj}}(j=x, y, z)$ in the appropriate direction,

- springs are elastic details; other parts of the automatic movement system are absolute solid objects,

- the effect of the gaps between dynamic joints is ignored.

Based on the actual weapon's construction, the links between parts of it, and the assumptions mentioned above, a computational model of a gas-operated automatic weapon was created, see Fig. 1. Overall system status survey: the elevation angle is $\varphi$ and the traverser angle is $\beta$.

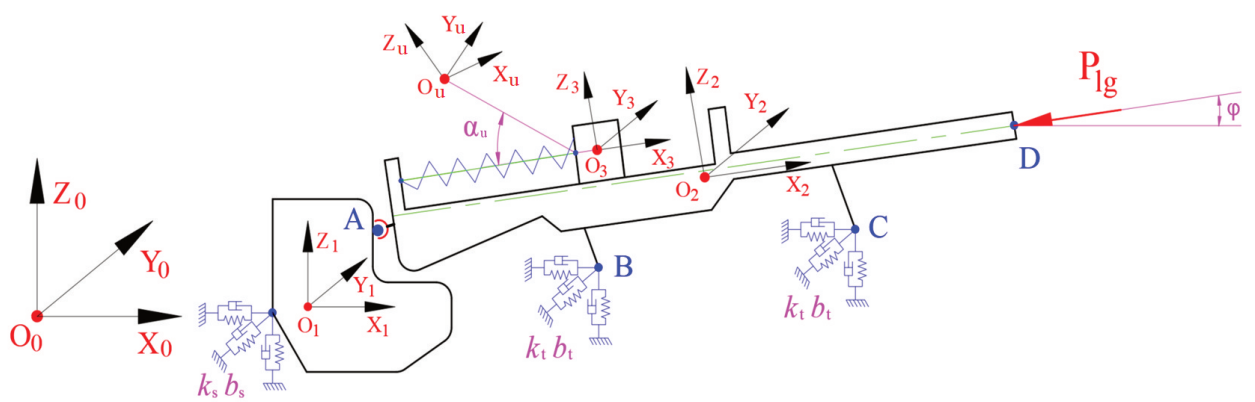

Fig. 1 The dynamic model of the Shooter-gas-operated automatic weapon system

The Shooter-weapon system includes three rigid bodies:

- body 1: shooter's shoulder is simulated by mass concentration $m_{1}$,

- body 2: the body of the gun (weapon frame) with mass $m_{2}$,

- body 3: basic mechanism (breech block carrier) with mass $m_{3}$.

It is necessary to take into consideration the working mechanism $u$ of the automatic system (whose movement depends on the movement of the basic mechanism) with 
mass $m_{u}$. For the AKM submachine gun, we consider the main working mechanism that greatly affects the basic mechanism movement, which is the bolt. The mass, center of gravity, and moment of inertia of all bodies were determined using Solidworks software.

To investigate the system of rigid body dynamics, Cartesian coordinate systems have been established at the mass center of each body and of the whole system as shown in Fig. 1, where:

- $R_{0}=\left(O_{0} X_{0} Y_{0} Z_{0}\right)$ : represents the stationary coordinate of the system connected to the Earth,

- $R_{v}=\left(O_{v} X_{v} Y_{v} Z_{v}\right)$ : the local coordinate system established at the $v$-th rigid body, for $v=1,2,3, \ldots, u$.

From the assumptions and kinetic constraints between objects, the system has 8 generalized coordinates: $\left[q_{j}\right]=\left[q_{1}, q_{2}, q_{3}, q_{4}, q_{5}, q_{6}, q_{7}, q_{u}\right]$, in which: $q_{1}$ - longitudinal displacement of body 1 along $X_{0}$-axis; $q_{2}$ - longitudinal displacement of body 1 about $Y_{0}-$ axis; $q_{3}$ - longitudinal displacement of body 1 about $Z_{0}$-axis; $q_{4}$ - angular displacement of body 2 about $X_{1}$-axis; $q_{5}$ - angular displacement of body 2 about $Y_{1}$-axis; $q_{6}-$ angular displacement of body 2 about $Z_{1}$-axis; $q_{7}$ - longitudinal displacement of body 3 along $X_{2}$-axis; $q_{k}$ - longitudinal displacement or angular displacement of body $u$ about $X_{u}$-axis.

The examined Shooter-weapon system has seven degrees of freedom and eight generalized coordinates, in which the independent generalized coordinates are from $q_{1}$ to $q_{7}$. The other, $q_{u}$, is dependent.

\subsection{Application of Load}

The main active forces exerted in this model were the forces acting on the weapon casing during firing operation, the force of the gunner's shoulder and hand, and the bodies' gravity.

- The forces acting on the casing of the weapon during the firing operation:

The forces acting on the weapon and causing the motion of all weapon parts to depend on the type of operation, see [6], are determined based on the knowledge of firing force acting on the barrel, on the gas chamber, and the functional cycle of the weapon. For a portable gas-operated automatic weapon, the definition and analysis of the forces acting on the weapon are described in detail in [6]. Its graph is given in Fig. 2. The forces shown in Fig. 2 are acting during one functional cycle, and their sum transmitted from weapon to the shooter is called weapon force action on the shooter. During burst firing, these forces are periodic, see [6].

$$
\boldsymbol{P}_{\mathrm{lg}}=\boldsymbol{F}_{\mathrm{H}}-\boldsymbol{F}_{\mathrm{PL}}+\boldsymbol{F}_{\mathrm{RZP}}+\boldsymbol{F}_{\mathrm{PP}}-\boldsymbol{F}_{\mathrm{RPP}}
$$

where

$\boldsymbol{F}_{\mathrm{H}}-$ the force of shot depending on the barrel gas pressure,

$\boldsymbol{F}_{\mathrm{PL}}-$ the force on the gas chamber,

$\boldsymbol{F}_{\mathrm{PP}}-$ the return spring force,

$\boldsymbol{F}_{\mathrm{RZP}}$ - the impact force when breech hits the rear of the weapon casing,

$\boldsymbol{F}_{\mathrm{RPP}}-$ the impact force when breech hits the front of the weapon casing.

- The forces of the shooter's shoulder and hand acting on the mechanical system when firing: 


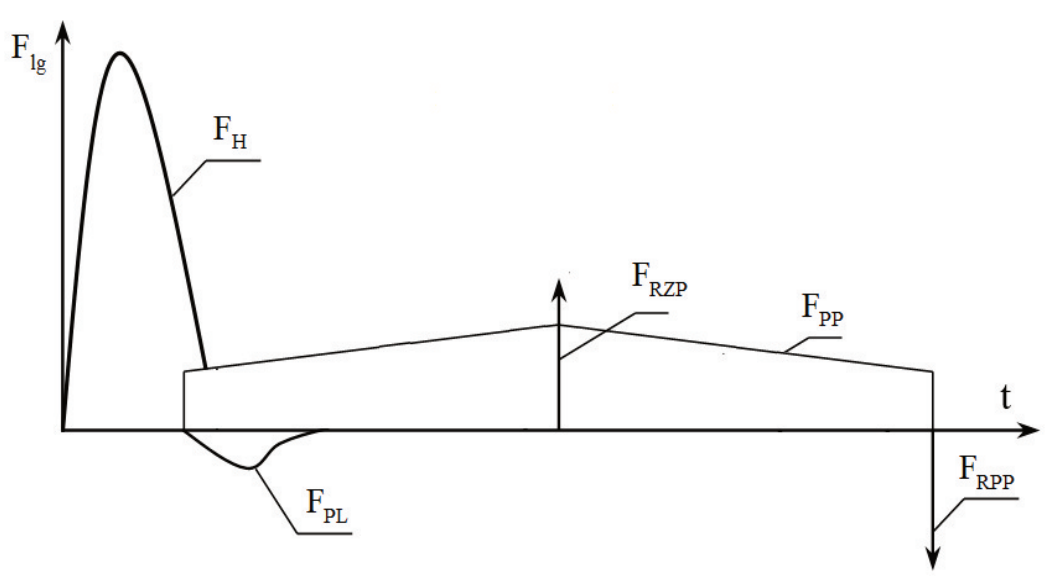

Fig. 2 Forces acting on the weapon casing of gas-operated weapon

During the firing process, the interaction between the human body and the machine gun system has a significant influence on the dynamic characteristics of the weapon, and they are defined as follows:

$$
\boldsymbol{F}_{\mathrm{s}}=\left[\left(k_{s x} q_{1}+b_{s x} \dot{q}_{1}\right),\left(k_{s y} q_{2}+b_{s y} \dot{q}_{2}\right),\left(k_{s z} q_{3}+b_{s z} \dot{q}_{3}\right)\right]^{\mathrm{T}}
$$

where $\boldsymbol{F}_{\mathrm{s}}$ - the force of the shooter's shoulder; $k_{s}, b_{s}$ - the stiffness and viscosity coefficient of the shooter's shoulder in three perpendicular directions, respectively.

$$
\boldsymbol{F}_{\mathrm{t}}=\left[k_{\mathrm{t} j}\left(R_{2 \mathrm{t} j}-R_{2 \mathrm{t} j 0}\right)+b_{\mathrm{t} j} \dot{R}_{2 \mathrm{t} j}\right]^{\mathrm{T}}, j=x, y, z
$$

where $\boldsymbol{F}_{\mathrm{t}}$ - the force of the shooter's hand; $k_{\mathrm{t}}, b_{\mathrm{t}}-$ the stiffness and viscosity coefficient of the shooter's hand in three perpendicular directions, respectively; $R_{2 t 0}$ is the original position of the shooter's hand when holding the gun in the fixed coordinate system $O_{0}$, position $\mathrm{B}$ and $\mathrm{C}$ in Fig. 1 (balanced position). $R_{2 \mathrm{t}}$ is the position of the shooter's hand when holding the gun in the fixed coordinate system $O_{0}$ when firing:

$$
\boldsymbol{R}_{2 \mathrm{t}}=\boldsymbol{R}_{20}+\boldsymbol{A}_{20} \boldsymbol{u}_{\mathrm{t} 2}
$$

where $\boldsymbol{R}_{20}$ - the original position vector $O_{2}$ in the fixed coordinate system $O_{0} . A_{20}$ - the transfer matrix to determine the direction of the system $O_{2}$ compared to fixed system $O_{0}, \boldsymbol{u}_{\mathrm{t} 2}-$ the position vector of the shooter's hand when holding the gun in the moving coordinate system $\mathrm{O}_{2}$.

The values of $k_{\mathrm{s}}, b_{\mathrm{s}}, k_{\mathrm{t}}$, and $b_{\mathrm{t}}$ are determined according to the documents [1] and [7].

- The gravity of the bodies $\left(\boldsymbol{P}_{v}\right)$ :

Force of the gravity in $v$-th body is placed at the center, is perpendicular to the horizontal plane $O X Y$ and the direction is vertically downwards. The magnitude of this force is determined as follows:

$$
P_{v}=m_{v} g
$$

where $m_{v}$ - the mass of the $v$-th solid object, $g$ - the acceleration of gravity. 


\subsection{Establishes the System of Differential Equations for Mechanical System}

In this study, we have chosen Lagrange's method. Lagrange's differential equations system describes the motion of the mechanical system as follows, see [8]:

$$
\frac{\mathrm{d}}{\mathrm{d} t} \frac{\partial T}{\partial \dot{q}_{j}}-\frac{\partial T}{\partial q_{j}}=Q_{j}
$$

where $T$ - the total kinetic energy of the whole mechanical system; $q_{j}$ - the generalized coordinate; $Q_{j}$ - the generalized force corresponding to the generalized coordinates $q_{j}$. A detailed explanation of the total kinetic energy of the whole mechanical system and generalized force can be obtained from [7] and [8].

After determining the kinetic energy $(T)$ and generalized force $\left(Q_{j}\right)$ of the mechanical system, we obtain a system of 8 differential equations of the $2^{\text {nd }}$ order in Lagrange Eq. (6).

Using dynamic links of elements $u$ with body 3 through the transmission ratio $i$ and performance $\eta$, according to [9], we have the following relationship:

$$
\begin{gathered}
\dot{q}_{u}=i \dot{q}_{7} \Rightarrow \ddot{q}_{u}=i \ddot{q}_{7}+\dot{q}_{7} \frac{\mathrm{d} i}{\mathrm{~d} t} \\
\frac{\mathrm{d} i}{\mathrm{~d} t}=\frac{\mathrm{d} i}{\mathrm{~d} q_{7}} \cdot \frac{\mathrm{d} q_{7}}{\mathrm{~d} t}=\dot{q}_{7} \frac{\mathrm{d} i}{\mathrm{~d} q_{7}}
\end{gathered}
$$

Substituting Eq. (8) into Eq. (7) gives:

$$
\ddot{q}_{u}=i \ddot{q}_{7}+\dot{q}_{7}^{2} \frac{\mathrm{d} i}{\mathrm{~d} q_{7}}
$$

On the other hand, we have :

$$
\eta=\frac{R_{u}^{*} \cdot \mathrm{d} q_{u}}{R_{3}^{*} \cdot \mathrm{d} q_{7}}=i \frac{R_{u}^{*}}{R_{3}^{*}} \Rightarrow R_{3}^{*}=R_{u}^{*} \frac{i}{\eta}
$$

where $R_{3}^{*}, R_{u}^{*},-$ the total thrust and drag acting on body 3 and body $u$.

$$
\left.\begin{array}{l}
R_{3}^{*}=Q_{3}-m_{3} \ddot{q}_{7} \\
R_{u}^{*}=Q_{u}-m_{u} \ddot{q}_{u}
\end{array}\right\}
$$

$Q_{3}, Q_{u}$ - the external force acting on body 3 and body $u$.

By substituting formulas Eqs (7)-(11) into the system of differential Eq. (6), after arrangement, we get a system of seven differential equations of the second order:

$$
E Q S=\left\{e q_{1}, e q_{2}, e q_{3}, e q_{4}, e q_{5}, e q_{6}, e q_{7}\right\}
$$

\section{Problem Solution}

When solving Eq. (12), we must first determine the system's input parameters: parameters of internal ballistics, structure parameters, parameters of the shooter's connection with the weapon, functional cycle, and dynamic characteristics of weapon mechanisms. Dimensional and mass characteristics were determined by measurement directly on the weapon or they were obtained from the technical documentation. 
Mass moments of inertia, force, and center of gravity were determined by SolidWorks software, see Fig. 3.

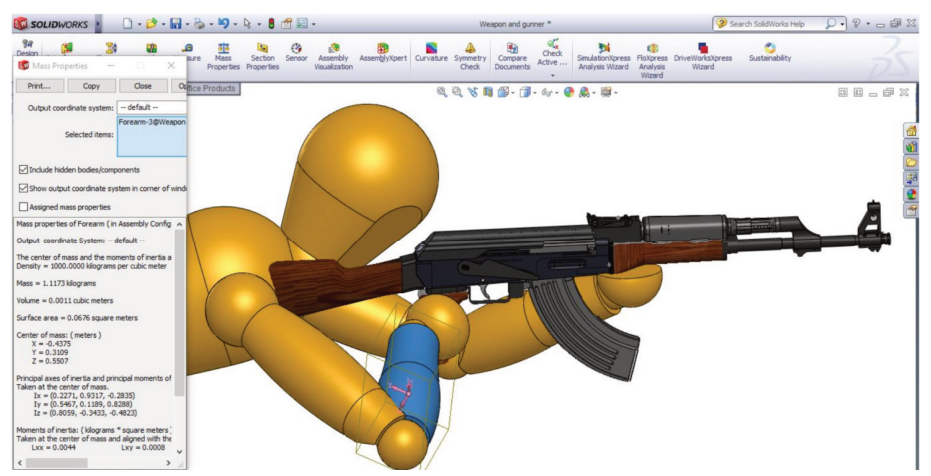

Fig. 3 Determination of the input parameters using Solidworks software

The above mechanical model describing oscillation gun when firing is validated for AKM submachine gun, and the human body model was chosen of following physical condition: $1.65 \mathrm{~m}$ of the height, $66 \mathrm{~kg}$ of weight. Input parameters of the system are determined in [1], and the motion equations system Eq. (12) has been solved by numerical integration method. Due to the vast number of inputs, only the most critical parameters are mentioned hereto, see Tabs 1-3.

Tab. 1 Mass and moment of inertia of the objects in the model

\begin{tabular}{|c|c|c|c|c|c|c|c|}
\hline Body & $\begin{array}{c}\text { Mass } \\
{[\mathrm{kg}]}\end{array}$ & $\begin{array}{c}J_{x} \\
{\left[\mathrm{~kg} \cdot \mathrm{m}^{2}\right]}\end{array}$ & $\begin{array}{c}J_{y} \\
{\left[\mathrm{~kg} \cdot \mathrm{m}^{2}\right]}\end{array}$ & $\begin{array}{c}J_{z} \\
{\left[\mathrm{~kg} \cdot \mathrm{m}^{2}\right]}\end{array}$ & $\begin{array}{c}J_{x y} \\
{\left[\mathrm{~kg} \cdot \mathrm{m}^{2}\right]}\end{array}$ & $\begin{array}{c}J_{x z} \\
{\left[\mathrm{~kg} \cdot \mathrm{m}^{2}\right]}\end{array}$ & $\begin{array}{c}J_{y z} \\
{\left[\mathrm{~kg} \cdot \mathrm{m}^{2}\right]}\end{array}$ \\
\hline \hline 1 & 20 & - & - & - & - & - & - \\
\hline 2 & 2.9 & $42 \times 10^{-4}$ & $127 \times 10^{-3}$ & $93 \times 10^{-3}$ & $-5 \times 10^{-5}$ & $8 \times 10^{-3}$ & 0 \\
\hline 3 & 0.42 & $72 \times 10^{-6}$ & $384 \times 10^{-5}$ & $384 \times 10^{-5}$ & $11 \times 10^{-6}$ & $236 \times 10^{-6}$ & 0 \\
\hline $\mathrm{k}$ & 0.084 & $34 \times 10^{-7}$ & $66 \times 10^{-6}$ & $66 \times 10^{-6}$ & $14 \times 10^{-7}$ & $9 \times 10^{-7}$ & 0 \\
\hline
\end{tabular}

Tab. 2 Parameters of elasticity and viscous resistance

\begin{tabular}{|l|c|c|}
\hline \multicolumn{1}{|c|}{ Description } & Symbol & Value \\
\hline \hline Stiffness of shooter's shoulder joint & $k_{\mathrm{s}}$ & $(1300 \div 1900) \mathrm{N} \mathrm{m}^{-1}$ \\
\hline Stiffness of shooter's hand & $k_{\mathrm{t}}$ & $(500 \div 800) \mathrm{N} \mathrm{m}^{-1}$ \\
\hline Damping coefficients of shooter's shoulder joint & $b_{\mathrm{s}}$ & $(1000 \div 6000) \mathrm{N} \mathrm{s} \mathrm{m}^{-1}$ \\
\hline Damping coefficients of shooter's hand & $b_{\mathrm{t}}$ & $(500 \div 1500) \mathrm{N} \mathrm{s} \mathrm{m}^{-1}$ \\
\hline
\end{tabular}

The system of Eq. (12) is solved in combination with the equations of internal ballistics using Matlab software using the Runge-Kutta method of the fourth-order. One of the parameters used as an evaluation criterion for stability, ability to work safely and reliably is the deviation of the angle of elevation (in the vertical plane) and the deviation of the angle of measurement (in the horizontal plane) [10-12]. These parameters were selected to compare and evaluate the proposed dynamic model with the corresponding experimental data. Three shots with a range and a measurement close to zero are considered. 
Tab. 3 Parameters of internal ballistics of AKM submachine gun

\begin{tabular}{|l|c|c|}
\hline \multicolumn{1}{|c|}{ Description } & Symbol & Value \\
\hline \hline Caliber of gun & $d$ & $7.62 \times 10^{-3} \mathrm{~m}$ \\
\hline Mass of powder charge & $\omega_{\mathrm{t}}$ & $1.67 \times 10^{-3} \mathrm{~kg}$ \\
\hline Initial volume of the combustion chamber & $W_{0}$ & $2.18 \times 10^{-6} \mathrm{~m}^{3}$ \\
\hline Displacement of the projectile inside the barrel & $l_{\mathrm{d}}$ & $0.37 \mathrm{~m}$ \\
\hline $\begin{array}{l}\text { Distance between the initial position of the base of } \\
\text { the projectile and the position of the gas vent }\end{array}$ & $l_{\phi}$ & $0.27 \mathrm{~m}$ \\
\hline Diameter of the gas vent & $d_{\phi}$ & $4 \times 10^{-3} \mathrm{~m}$ \\
\hline Diameter of piston & $d_{\mathrm{p}}$ & $1.4 \times 10^{-2} \mathrm{~m}$ \\
\hline Initial volume of the gas cylinder & $W_{\mathrm{b} 0}$ & $2.3 \times 10^{-6} \mathrm{~m}^{3}$ \\
\hline Projectile mass & $m_{\mathrm{d}}$ & $7.9 \times 10^{-3} \mathrm{~kg}$ \\
\hline Mass of the cartridge & $m_{\mathrm{vd}}$ & $16.4 \times 10^{-3} \mathrm{~kg}$ \\
\hline Mass of the cartridge case & $m_{\mathrm{v}}$ & $7.2 \times 10^{-3} \mathrm{~kg}^{-1}$ \\
\hline Stiffness of return spring & $C_{0}$ & $300 \mathrm{~N} \mathrm{~m}^{-1}$ \\
\hline Initial compression force of the return spring & $\Pi_{0}$ & $30 \mathrm{~N}^{-1}$ \\
\hline Specific energy of powder & $E$ & $98 \times 10^{3} \mathrm{~J} \mathrm{~kg}^{-1}$ \\
\hline Powder density & $\Delta$ & $1.6 \times 10^{4} \mathrm{~N} \mathrm{~m}^{-3}$ \\
\hline Co-volume of powder gas & $A$ & $10^{-4} \mathrm{~m}^{3} \mathrm{~N}^{-1}$ \\
\hline Total pressure impulse & $I_{\mathrm{k}}$ & $137.5 \times 10^{3} \mathrm{~Pa} \mathrm{~s}$ \\
\hline Coefficient of fictitious projectile mass & $\Phi$ & 1.206 \\
\hline
\end{tabular}

Figs 4-7 show the curves of the velocity and displacement of the breech block carrier (Fig. 4), the change of the angle of elevation of the weapon in the vertical plane (Fig. 5), the change of the angle of traverse of the weapon in the horizontal plane (Fig. 6), and finally the linear displacement of the weapon backward (Fig. 7).

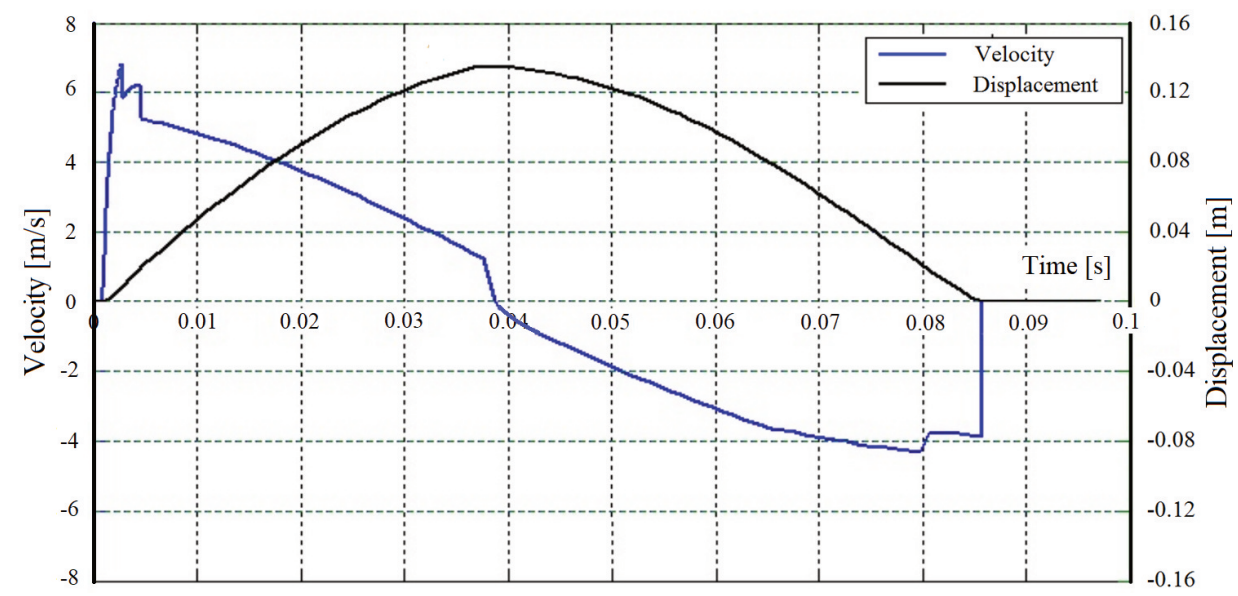

Fig. 4 Functional diagram of AKM submachine gun 


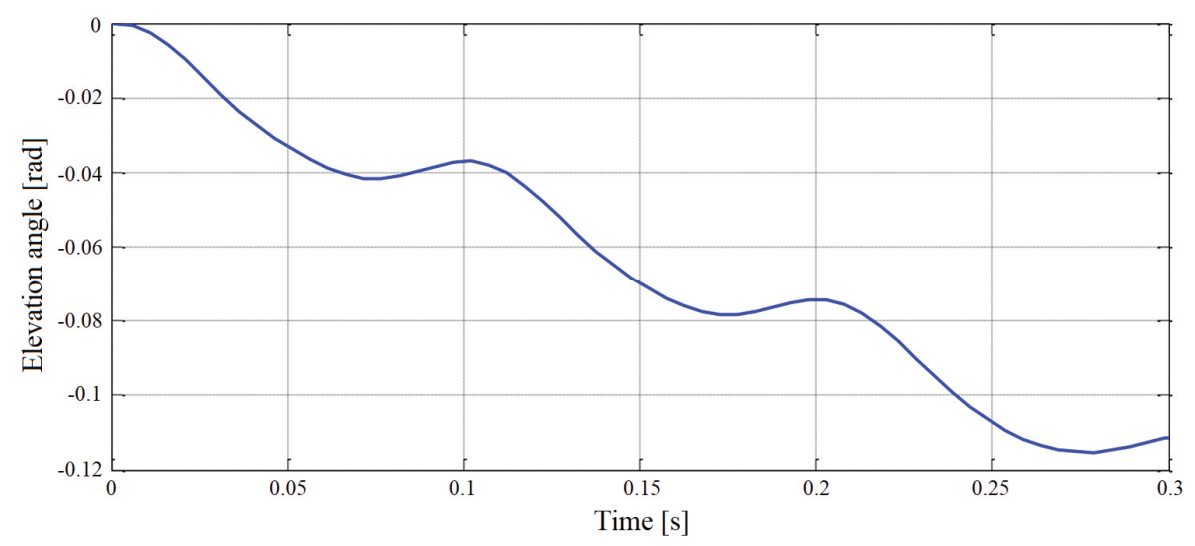

Fig. 5 Change of angle elevation

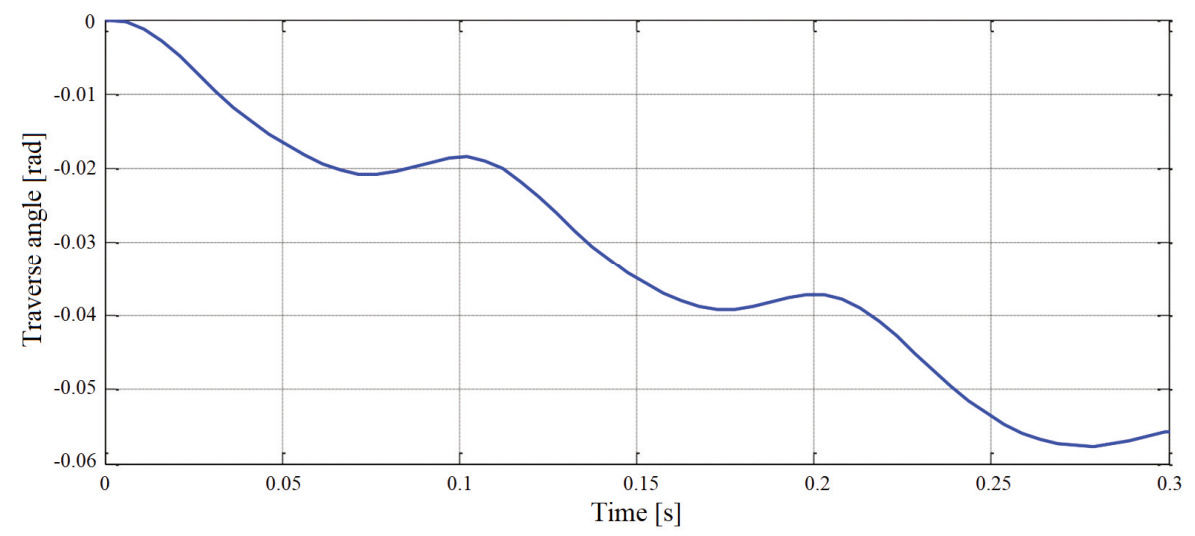

Fig. 6 Change of traverse angle

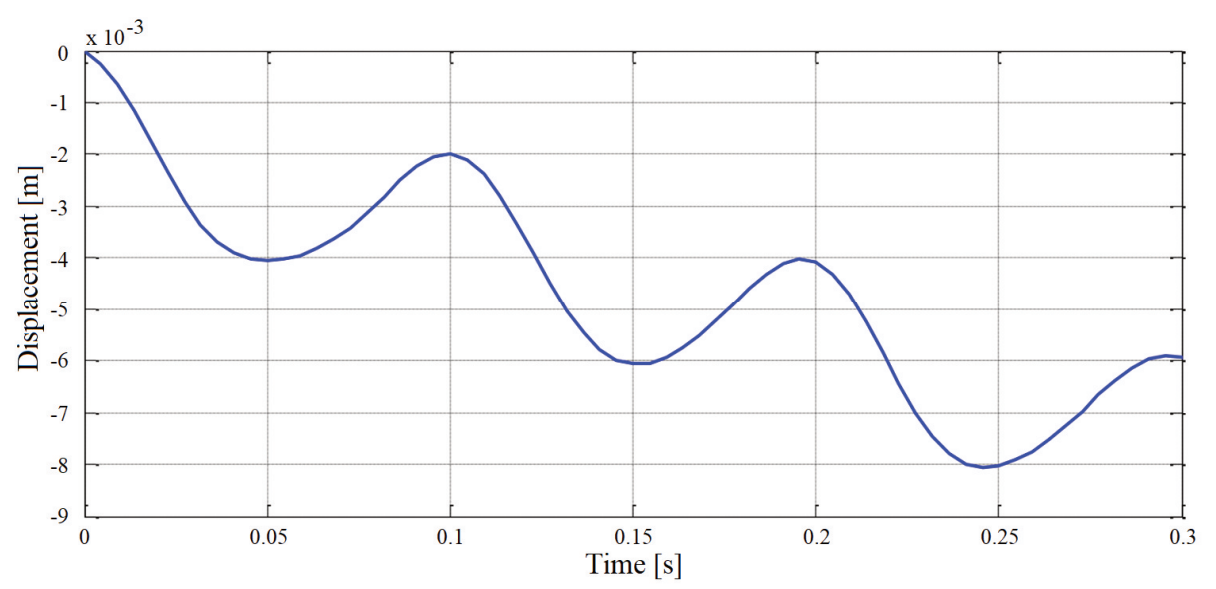

Fig. 7 Linear displacement of gun 


\section{Assessing Reliability of the Established Model}

To evaluate the above model's reliability, the authors performed experimental measurements on an AKM submachine gun and compared their results with the calculated ones. The arrangement of the technical experiment is shown in Fig. 8.

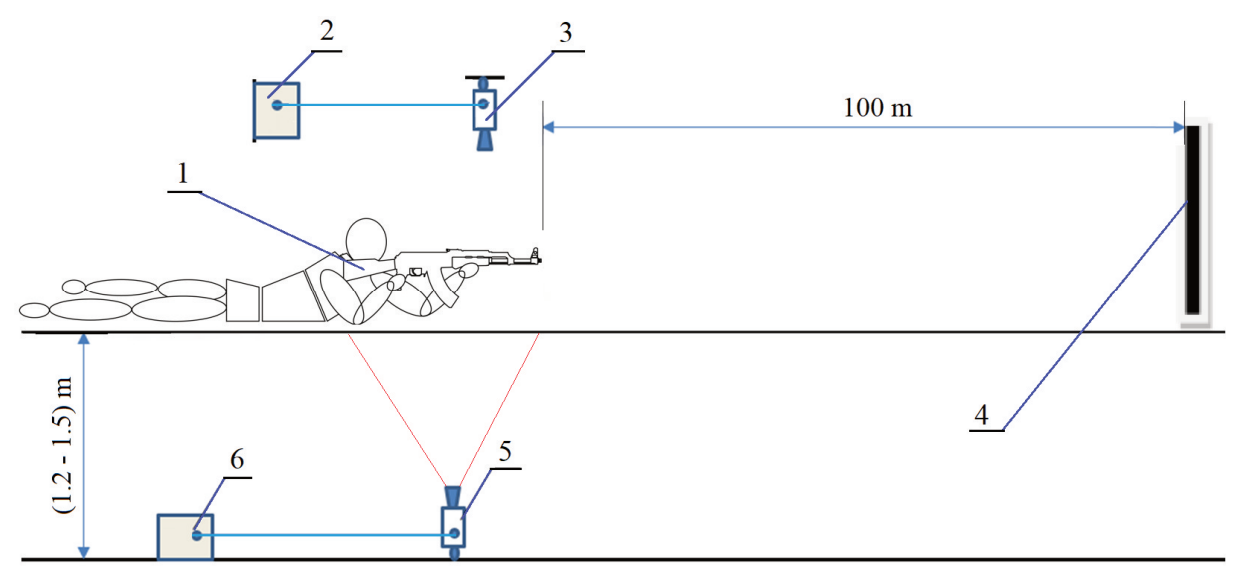

Fig. 8 Schematic of the experimental setup

1. Shooter-weapon system; $2 \& 6$. computer; $3 \& 5$. high-speed camera; 4. target

Two high-speed cameras Fast-cam SA1.1, model 675K - C1 were used. The basic parameters of the high-speed camera FASTCAM SA1.1 are shown in Tab. 4. The first camera (No. 3) was to record the horizontal displacement, see Fig. 9. The other one (No. 5) was located on the site to record the vertical barrel displacement, see Fig. 10. The field of the high-speed camera view was set up to allow continuous observation of marker motion during firing. Based on the recordings, it was possible to define the gun barrel's displacement in the vertical and horizontal plane. These devices are connected to the computers. The TEMA software was used to process the recordings as well as to collect the required data. Experimental conditions: the temperature from $25{ }^{\circ} \mathrm{C}$ to $30{ }^{\circ} \mathrm{C}$, the humidity of $70 \%$. The shooter selected for the experiment was of a height of $1.65 \mathrm{~m}$ and a weight of $66 \mathrm{~kg}$.

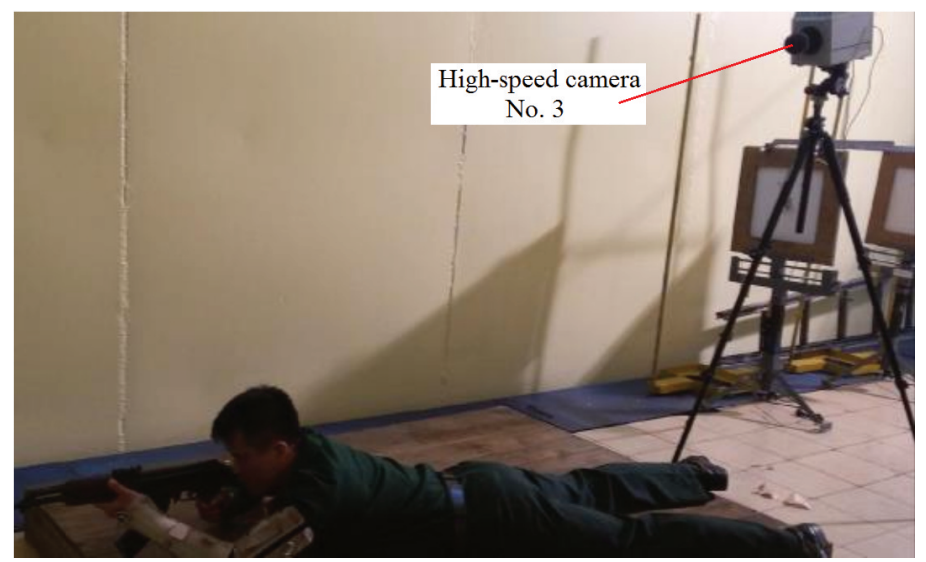

Fig. 9 Position of camera SA1.1 measures horizontal displacement 


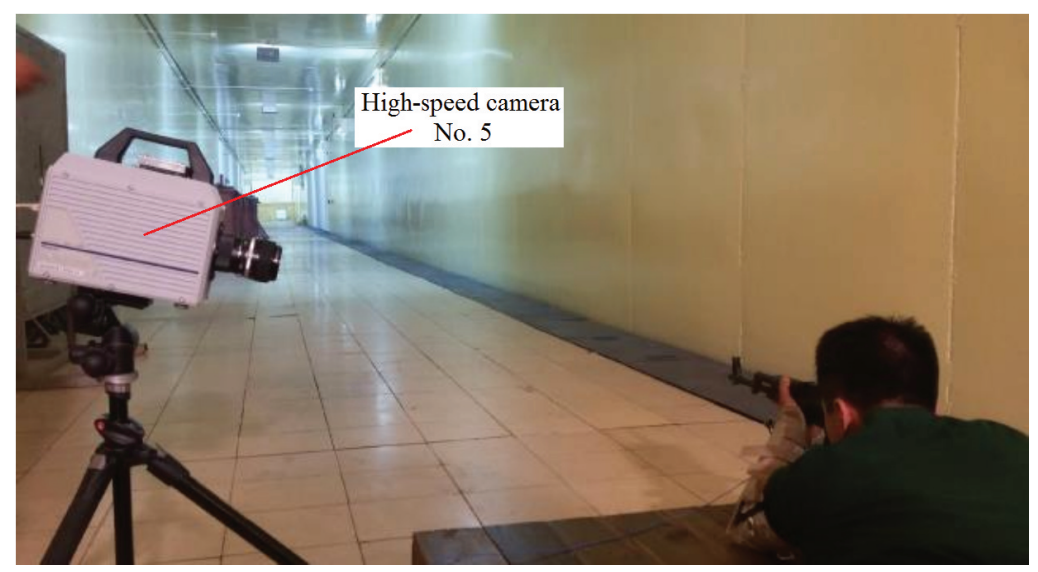

Fig. 10 Position of camera SA1.1 measures vertical displacement

Tab. 4 Basic parameters of the high-speed cameras Fastcam SA1.1

\begin{tabular}{|l|l|}
\hline Cameras Fast-cam SA1.1 & \multicolumn{1}{|c|}{ Description } \\
\hline & Maximum frame rate 675 000 fps (frame per second). \\
\cline { 2 - 2 } & $\begin{array}{l}\text { Data memory: } 8 \mathrm{~GB} \text { equivalent to } 5457 \text { frame } \\
64 \times 16 \text { pixels or 5 400 frame } 1024 \times 1024 \text { pixels. }\end{array}$ \\
\cline { 2 - 2 } & Sensor: 12 bit DAC. \\
\hline
\end{tabular}

There is always a difference between the result of a measurement and the true value of the quantity to be measured in practice. Therefore, it is necessary to approximate the measured values by a certain function. Method of least squares is often used to define these functions [13]. Fig. 11 shows the results of the experimental treatment between the measured result and the approximate curve.

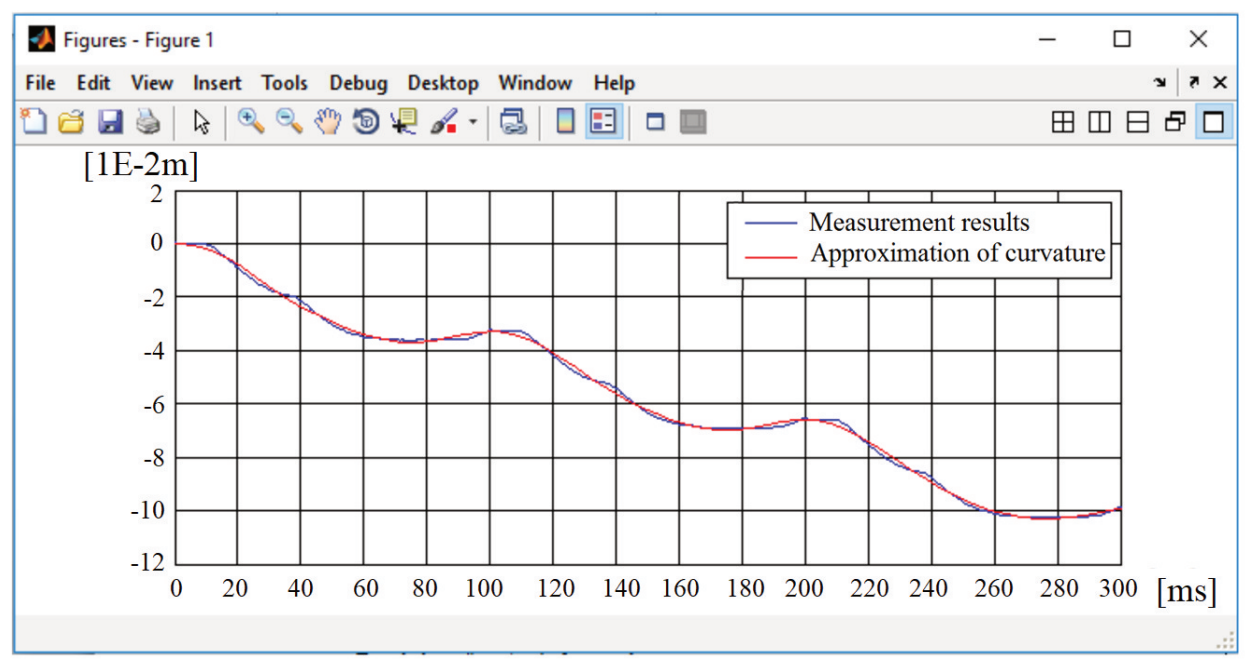

Fig. 11 Curve approximation of measurement results 
The results of the solution of evaluation and traverse angle in firing at bursts of three rounds are compared with the experimentally obtained data. The deviation between calculation results and experimental results is shown in Figs 12 and 13.

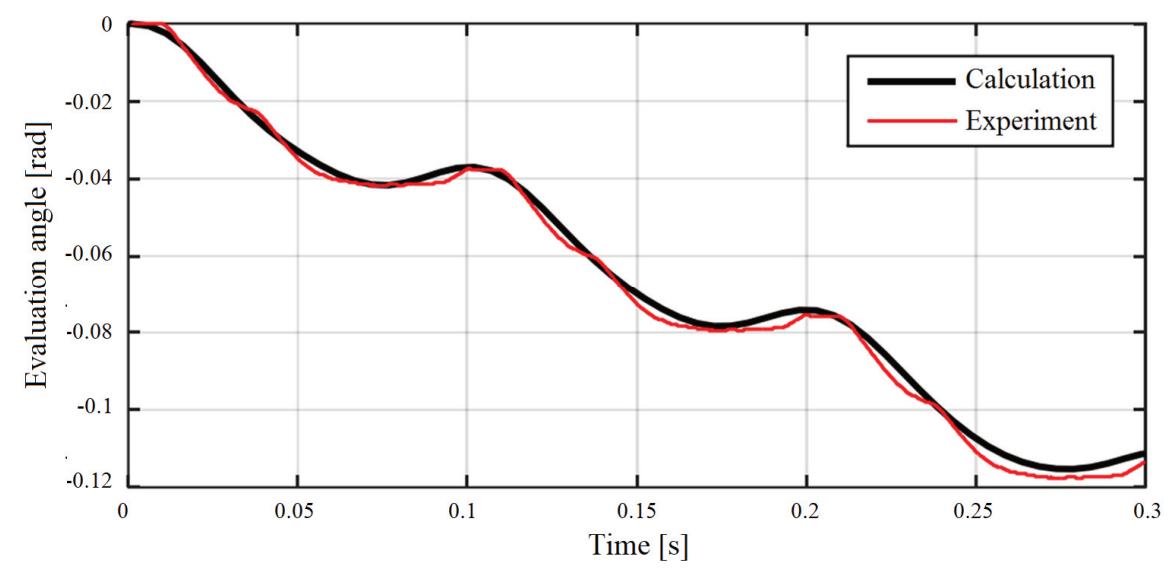

Fig. 12 Change of angle elevation

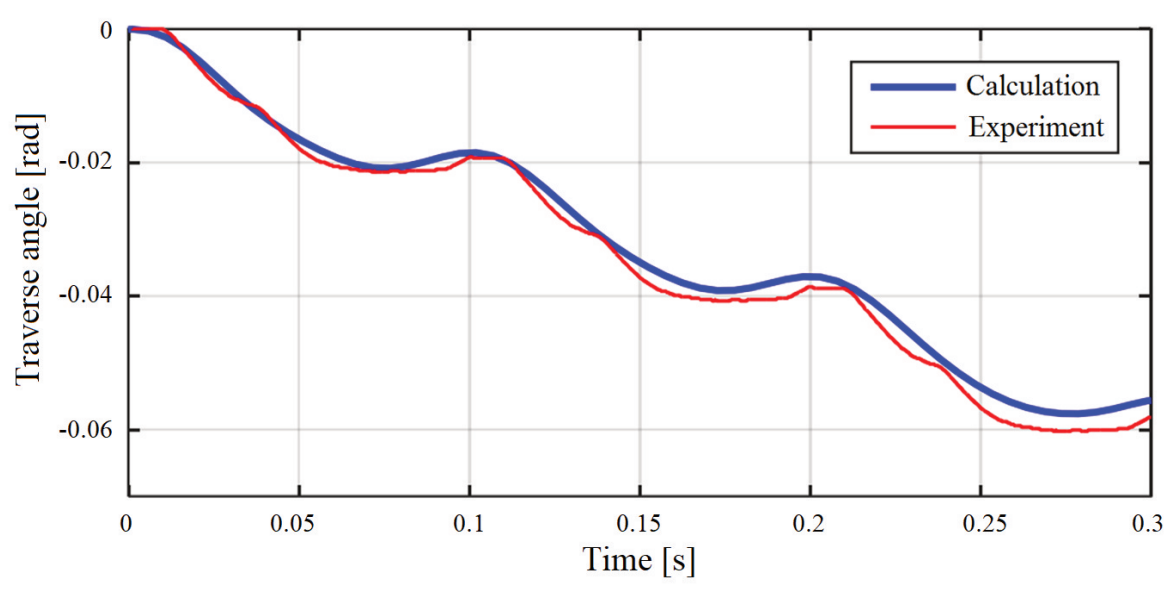

Fig. 13 Change of traverse angle

\section{Comment}

The cycle time per shooting is $0.09925 \mathrm{~s}$, equivalent to the theory rate of fire of 604.5 rounds $\min ^{-1}$ (Fig. 4). The fire rate in the manufacturer's document is 600 rounds $\mathrm{min}^{-1}$ ), error of $0.75 \%$.

The comparisons show a very good agreement between the results of the calculation and experimental results. The amplitude of vibration is calculated according to the model, and the experimental results are relatively similar. The maximum amplitude deviation on the vertical plane does not exceed $2.2 \%$ (Fig. 12), while in the horizontal plane it does not exceed $8.4 \%$ (Fig. 13). The analysis results show that the established model of the mechanical system is completely consistent with reality. The simultaneous solution of the internal ballistics problem, the dynamics problem of the automatic 
system, and the vibration problem of the Shooter-weapon system when firing have resulted in more general perspective on the operation of the whole system.

The difference between theoretical calculation results and measurement results comes from the following reasons:

- errors when calculating theory: When building a computational model, we gave some assumptions to simplify the calculation process; in the calculation, the process still must use some assumptions, approximate formulas; error due to numerical methods to calculate. Errors caused by inaccurate input data, see [12],

- experimental errors: Guns are not new; experimental guns are level 2 guns; errors due to the measuring equipment and the measuring conditions, see [14-15].

\section{Effect of Some Structural Parameters on the Firing Stability}

\subsection{The Effects of Holding a Gun}

For each shooter, holding a gun is different. Consider two postures of holding guns of the left hand with holding positions of $0.05 \mathrm{~m}$ apart, as shown in Fig. 14.

By solving Eq. (12) with the change in position of the shooter's left hand when holding the gun and at the same time maintaining other parameters, we can determine the law of the change of the angle of elevation of the weapon in the vertical plane (Fig. 15), the change of the angle of traverse of the weapon in the horizontal plane (Fig. 16), and finally the linear displacement of the weapon backward (Fig. 17).

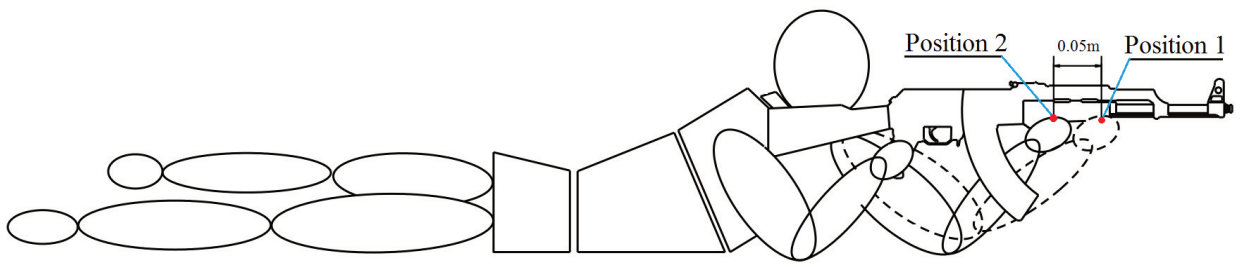

Fig. 14 Change in position of the shooter's left hand when holding the gun

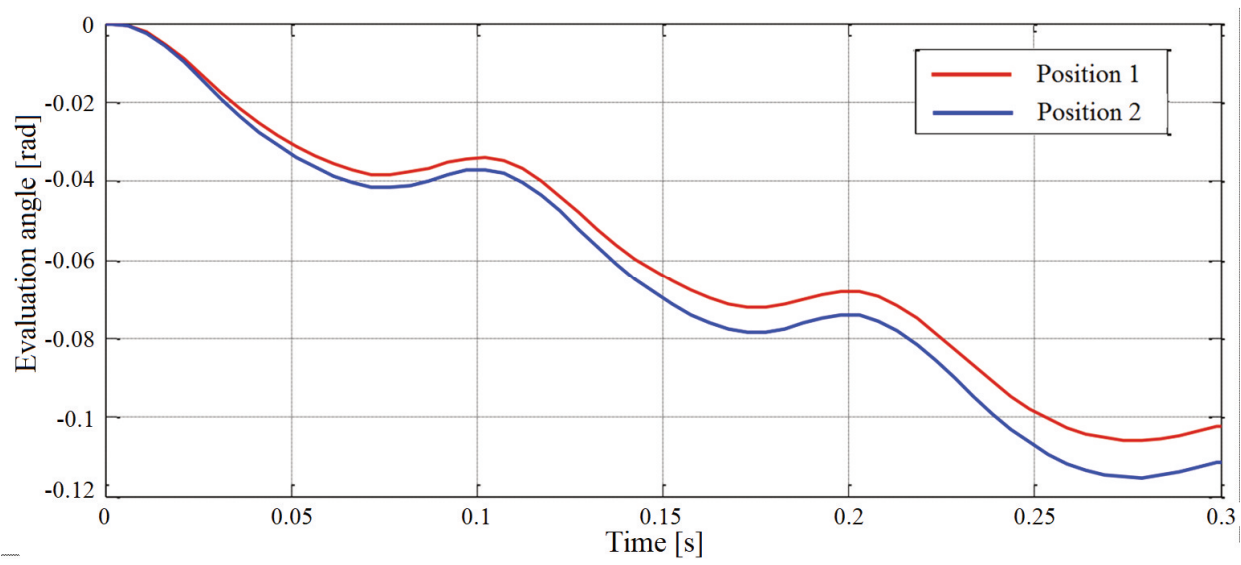

Fig. 15 Change of angle elevation 


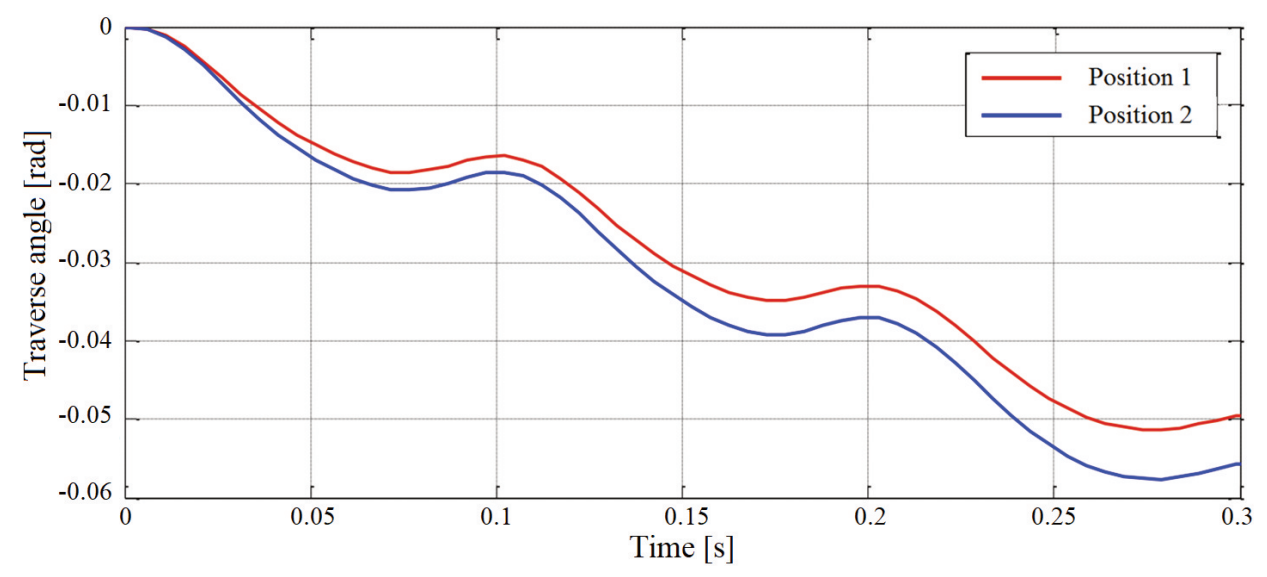

Fig. 16 Change of traverse angle

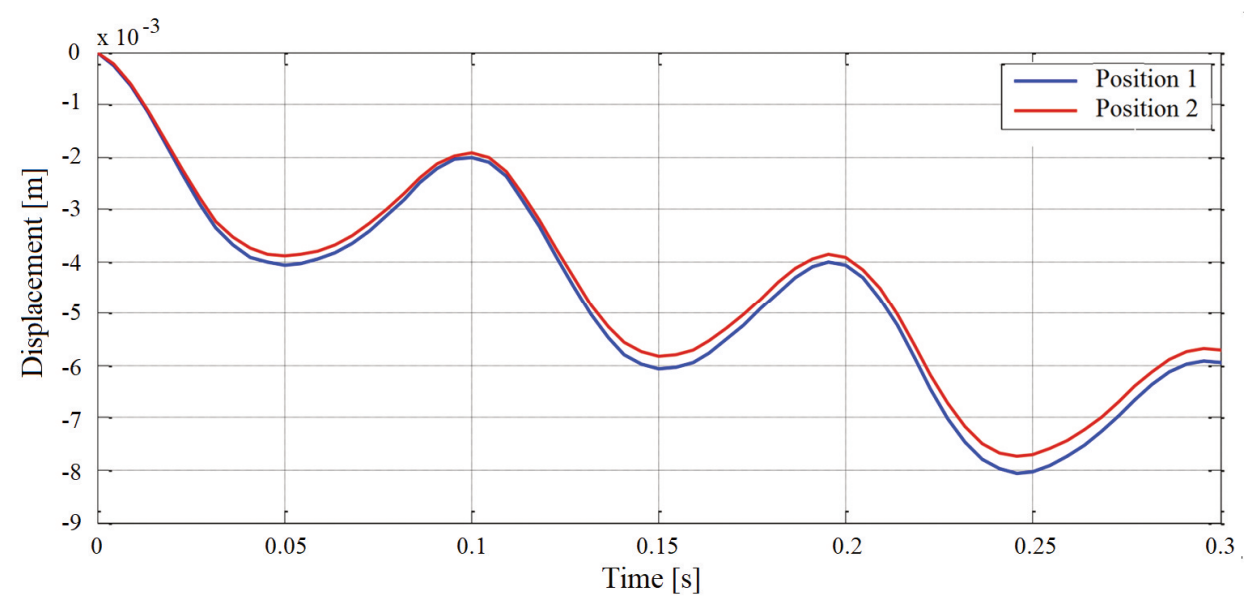

Fig. 17 Linear displacement of gun

\section{Comment}

When the change in position of the shooter's left hand when holding the gun, the weapon's movements and bounce angle also change. The handle in position 1 tends to make the gun more stable, see Figs 15 and 16. However, in position 1, the weapon backward's linear displacement increases, but this increase is quite small, see Fig. 17.

\subsection{The Effect of the Elastic Gun Stock}

The shot's energy is applied to the shooter's shoulder through the gun stock at the shoulder point position. This force of recoil causes the weapon to destabilize, especially when burst firing. In addition, the recoil force also affects the health of the shooter. Therefore, it is necessary to take measures to reduce this force. Various solutions have been proposed, such as mounting elastic material in a gun stock. However, this method is not highly durable and difficult to adjust. Therefore, a gun stock is designed with a spring-loaded shock absorber for the right choice. Currently, modern automatic guns 
are designed with resilient gun stock. For AKM submachine gun, the stock is made of wood or plastic, so the elasticity is not high. A solution for AKM submachine gun is shown in Fig. 18. The gun stock structure is split into 2 separate parts: one part is attached to the gun, the other part is used for the shoulder, and the two parts are linked together by an elastic spring system.

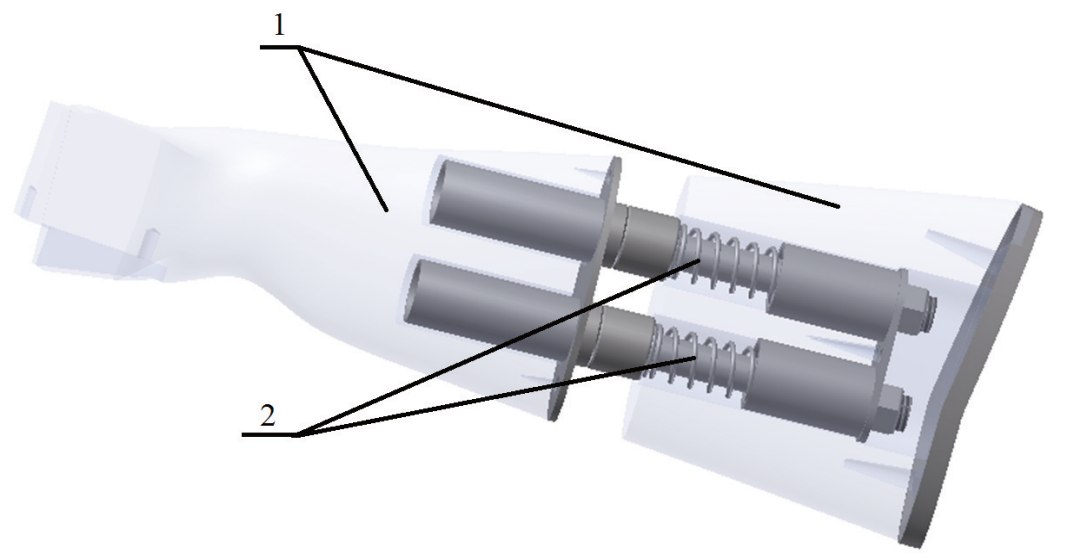

Fig. 18 Elastic gun stock structure; 1. the gun stock; 2. spring

Selection of spring with elastic coefficient is $k=300 \mathrm{~N} \mathrm{~m}^{-1}$, the stock's elastic coefficient is now:

$$
k_{\mathrm{b}}=k_{1}+k_{2}=2 k=600 \mathrm{Nm}^{-1}
$$

By solving Eq. (12) by changing the stock's elastic coefficient and at the same time maintaining other parameters, we can determine the law of the change of the angle of elevation of the weapon in the vertical plane (Fig. 19), the change of the angle of traverse of the weapon in the horizontal plane (Fig. 20), and finally the linear displacement of the weapon backward (Fig. 21).

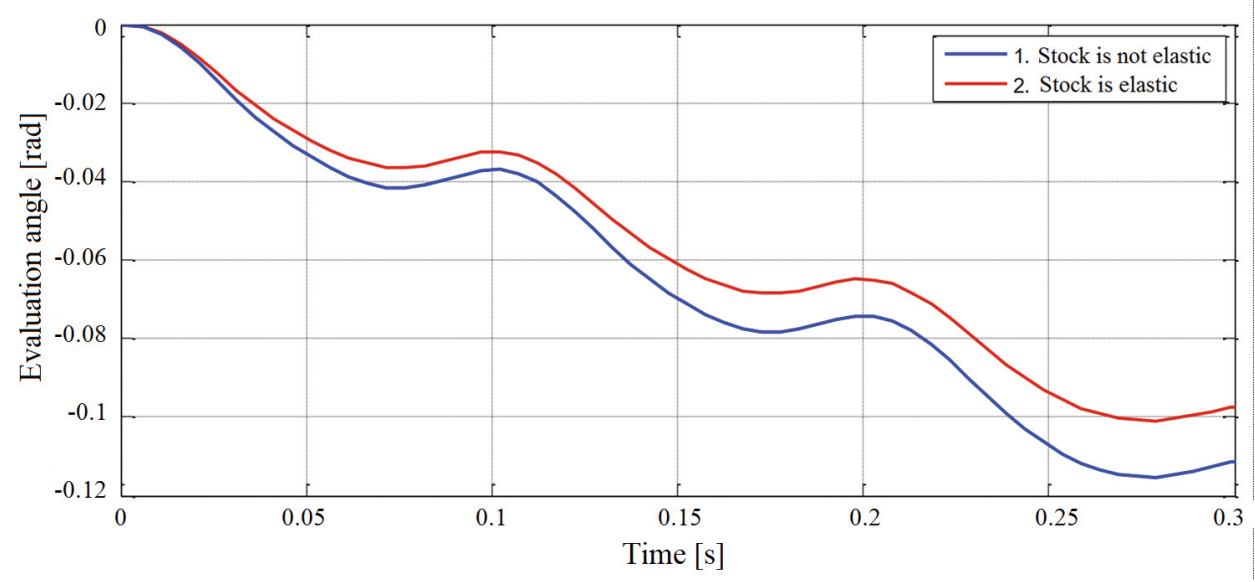

Fig. 19 Change of angle elevation 


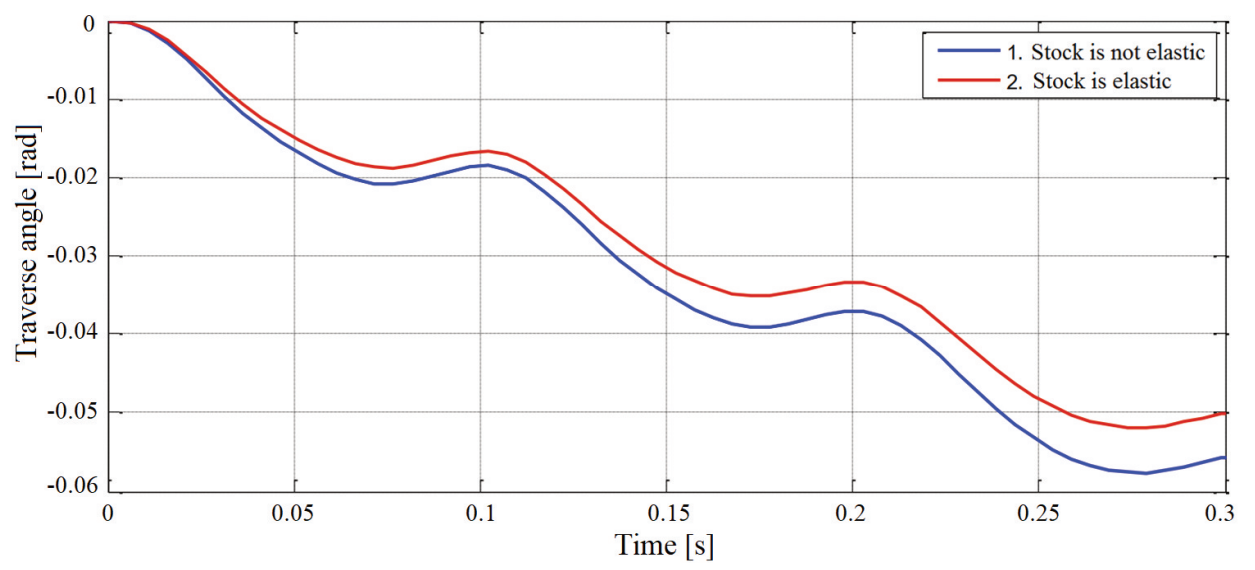

Fig. 20 Change of traverse angle

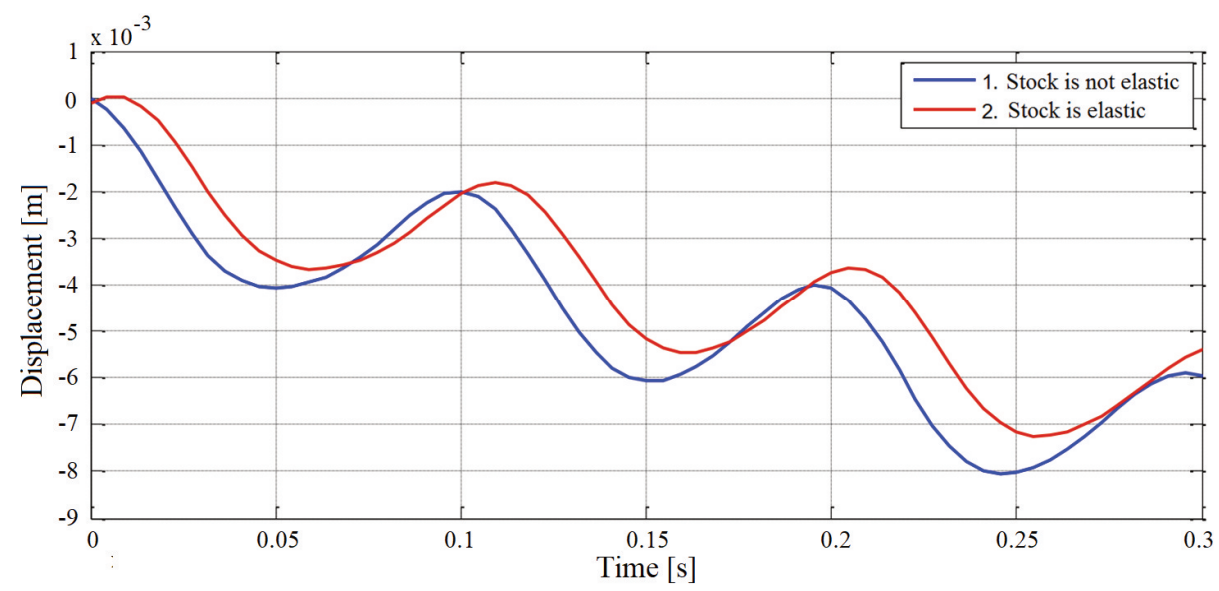

Fig. 21 Linear displacement of gun

\section{Comment}

The elastic gun stock influences the gun's stability when fired in the vertical or horizontal planes. When using an elastic stock, the gun is more stable when fired. The linear displacement of the weapon backward tends to decrease, and there is an unavoidable delay due to the spring's influence in the stock.

\section{Conclusion}

The paper presents a method for determining some parameters for evaluating the firing stability of the Shooter-weapon system when firing by modeling method based on the theory of multibody system dynamics and experimental methods. The dynamic model has been created for a portable gas-operated submachine gun and it contains three solids with seven degrees of freedom. In the dynamic model, in contrast to previous works, the influence of the shooter is solved by using elastic-damping links in the $x, y$, and $z$ axes, see Eqs (2) and (3). The use of the model helps to analyze and evaluate the effect of burst shooting on automatic weapons' stability more accurately. The compar- 
ison of theoretical and experimental results shows a very good accuracy and adequacy of the model. The obtained results will serve as a basis for further investigation of the influence of design parameters on the stability of the automatic weapon during firing and for the optimization of the overall structure of the portable gas-operated submachine gun.

\section{Acknowledgment}

The work presented in this paper has been supported by the Weapon Technology Centre and Faculty of Weapons, Le Quy Don Technical University in Hanoi, by the research project of the Ministry of Defense, and by the Research Support Project of the Department of weapon and ammunition, Faculty of Military Technology, University of Defence, Brno, Czech Republic.

\section{References}

[1] UONG, S.Q. Study of Possibilities of Improving the Accuracy of Portable Automatic Weapons (in Vietnamese) [PhD Thesis]. Hanoi: Military Technical Academy, 2009.

[2] LE, V.T. Study on the Oscillation of Handle Automatic Weapons when Firing and Analysis of Parameters Affecting the Weapon's Accuracy (in Vietnamese) [PhD Thesis]. Hanoi: Military Technical Academy, 1994.

[3] BALLA, J., M. HAVLICEK, L. JEDLICKA, Z. KRIST and F. RACEK. Dynamics of Automatic Weapon Mounted on the Tripod [online]. In: Proceedings of the $12^{\text {th }}$ WSEAS International Conference on Mathematical and Computational Methods in Science and Engineering (MACMESE' 10). Algarve, 2010, pp. 122127 [viewed 2020-09-21]. Avialable from: http://www.wseas.us/e-library/ conferences/2010/Faro/MACMESE/MACMESE-19.pdf

[4] PROCHAZKA, S. and M. NOVAK. Effect of Inertia Forces on Function of Automatic Weapon [online]. Advances in Military Technology, 2008, 3(2), pp. 48-54 [viewed 2020-08-21]. Available from: http://aimt.unob.cz/articles/08_02/ 08_02\%20(6).pdf

[5] BALLA, J. Dynamics of Mounted Automatic Cannon on Track Vehicle [online]. International Journal of Mathematical Models and Methods in Applied Sciences, 2011, 5(3), pp. 423-432 [viewed 2020-08-216]. Available from: https://www.naun.org/ main/NAUN/ijmmas/19-1152.pdf

[6] BALLA, J. Contribution to Determining Load Generated by Shooting from Automatic Weapons. In: International Conference on Military Technologies 2019. Brno: IEEE, 2019. DOI 10.1109/MILTECHS.2019.8870116.

[7] NGUYEN, T.D., D.V. NGUYEN, P.V. TA and L.D. DO. Biomechanical Analysis of the Shooter-Weapon System Oscillation. In: International Conference on Military Technologies 2017. Brno: IEEE, 2017. DOI 10.1109/MILTECHS. 2017.7988729.

[8] AHMED, A.S. Dynamics of Multibody Systems. $4^{\text {th }}$ ed. Chicago: University of Ilinois, 2013. ISBN 978-1-107-33721-6.

[9] PHAM, H.C. Dynamics of an Automatic Firing Gun (in Vietnamese). Hanoi: Military Technical Academy, 2002. 
[10] BALLA, J., Z. KRIST and I.C. LE. Experimental Study of Turret-Mounted Automatic Weapon Vibrations. International Journal of Mechanics, 2015, 9(1), pp.16-25. ISSN 1998-4448.

[11] BALLA, J., Z. KRIST, F. RACEK, P. MELSA, V. NEUMANN and I.C. LE. Analysis and Parameter Identification of Automatic Cannon Carriages. Defense Science Journal, 2018, 68(6), pp. 525-532. DOI 10.14429/dsj.68.12395.

[12] KONCZAK, J., K. BROMMANN and K.T. KALVERAM. Identification of TimeVarying Stiffness, Damping, and Equilibrium Position in Human Forearm Movements. Motor Control, 1999, 3(4), pp. 394-413. DOI 10.1123/mcj.3.4.394.

[13] NGUYEN, T.D., H.L. NGUYEN and T.T. BUI. Measure and Test Weapons (in Vietnamese). Hanoi: Military Technical Academy, 2007.

[14] VITEK, R. Analyses of the Measurement Accuracy of the Optical Light Gates. In: International Conference on Military Technologies 2019. Brno: IEEE, 2019. DOI 10.1109/MILTECHS.2019.8870114.

[15] VO, V.B., S. BEER, S.T. NGO, P.D. NGUYEN. The Effect of the Nozzle Ultimate Section Diameter on Interior Ballistics of HV-76 Trial Gun. In: International Conference on Military Technologies 2019. Brno: IEEE, 2019. DOI 10.1109/MILTECHS.2019.8870040. 